\title{
EDITORIAL
}

\section{VIH Y SIDA EN ESPAÑA}

\section{Lourdes Chamorro}

Secretaría del Plan Nacional sobre el Sida. Ministerio Sanidad y Consumo

La epidemia del virus de la inmunodeficiencia humana (VIH) o del síndrome de inmunodeficiencia adquirida, sida, ha experimentado numerosos cambios en sus casi 25 años de evolución. Entre los factores que han determinado estos cambios hay que destacar, sin duda alguna, la introducción de las terapias de alta eficacia en $1996^{1}$. Este hecho, considerado como uno de los mayores avances científicos de la historia de la terapéutica, determinó un claro punto de inflexión en el curso de la epidemia. Fue en ese momento cuando se produjo el principal cambio de tendencia en la incidencia de casos de $\operatorname{sida}^{2}$, iniciándose un descenso que todavía continúa aunque a un ritmo mucho más moderado. El descenso interanual entre 1996 y 1997 fue del 28\%, siendo entre 2002 y 2003 del 5,2\%. De hecho, en estos últimos años se podría hablar ya de una tendencia a la estabilización en la incidencia de los casos diagnosticados de sida ${ }^{3}$.

España dispone de un sistema de vigilancia epidemiológica de la incidencia de sida que se basa en la notificación de los casos diagnosticados, de ámbito estatal y que cubre a toda la población desde el inicio de la epidemia. Se trata de un sistema consolidado que ha permitido conocer la realidad del sida con un elevado nivel de cobertura y calidad de la información. Además, la definición de caso de sida utilizada es fruto de un consenso internacional que garantiza la comparabilidad de esta información con otros países ${ }^{4}$.
Este sistema nos permite conocer el número y las características de las personas diagnosticadas de sida y con ello valorar la realidad española respecto a la epidemia, pero se debe tener muy en cuenta que desde 1996 la medida de esta incidencia se encuentra necesariamente asociada al impacto que los tratamientos antirretrovirales están teniendo en la población, especialmente en el contexto de un sistema de salud como el nuestro en el que el acceso al tratamiento es universal y gratuito.

La infección por VIH suele cursar con una larga y silente historia natural. Desde que se contrae hasta que se desarrolla el sida transcurre un largo periodo de tiempo que continúa creciendo a medida que mejoran los tratamientos antirretrovirales ${ }^{5}$. Hoy en día en nuestro entorno podría darse, como modelo teórico, la situación en la que la incidencia de casos de sida disminuyera notablemente mientras las nuevas infecciones por VIH aumentaran de forma independiente. Por todo ello y para conocer la dimensión de la epidemia y planificar las actividades de prevención y las necesidades asistenciales y sociales resulta absolutamente necesario, sin que nadie lo ponga en duda ya, un sistema que permita monitorizar la situación epidemiológica de la infección por $\mathrm{VIH}^{6,7}$.

La vigilancia epidemiológica de las nuevas infecciones por VIH presenta, por diversos motivos, dificultades adicionales a las ya existentes en otros sistemas de información. 
La infección por VIH es, como se ha apuntado, habitualmente asintomática, lo que disminuye en gran medida su probabilidad de diagnóstico. De forma adicional la inadecuada percepción del riesgo en la población o el miedo a afrontar una enfermedad incurable o el estigma y la discriminación asociados, obstaculizan un diagnóstico temprano. Resulta preocupante observar cómo en un $38 \%$ de los casos de sida diagnosticados en $2003^{3}$, los pacientes desconocían previamente su seropositividad respecto al VIH, y cómo durante muchos años estas personas no han podido beneficiarse del seguimiento y tratamiento ni ser plenamente conscientes de la necesidad de protección de sus parejas sexuales. Esta proporción es del $58 \%$ en el caso de que la transmisión fuera por vía heterosexual ${ }^{3}$. A pesar de los diversos esfuerzos realizados en este sentido y del claro incremento en el número de pruebas el diagnóstico de la infección por VIH todavía no ha alcanzado en nuestro país los niveles deseables de normalización.

Otro factor particular y relevante a considerar en este sistema de información es la elevada proporción de personas que se repiten la prueba en numerosas ocasiones tras un primer diagnóstico positivo. Este hecho impone al sistema de vigilancia epidemiológica de nuevas infecciones por VIH la exigencia de un adecuado método de detección y eliminación de los duplicados ${ }^{8}$.

Y por último, excediendo el ámbito puramente técnico de la vigilancia epidemiológica, no se puede obviar que la realidad social del VIH/sida está teniendo una clara influencia sobre la capacidad de obtener la información necesaria para monitorizar la epidemia del VIH y planificar coherentemente las estrategias de prevención en nuestro país. Esta realidad, en la que lamentablemente todavía es posible observar la estigmatización de las personas con VIH o con sida y detectar casos de discriminación arbitraria, hace que exista en una parte de la sociedad civil resistencias a que se recoja este tipo de información o, más concretamente, a que se incluyan datos nominales en la misma.

Sin lugar a dudas la notificación de nuevos diagnósticos de VIH con base poblacional es la forma óptima para la vigilancia epidemiológica de la infección por VIH, y con ello la herramienta más útil para planificar las actividades de prevención y asistencia de la epidemia 9 .

Sin embargo, España se encuentra en la actualidad y por diversos motivos (muchos de ellos ligados a esa realidad social referida que interfiere con lo que debería ser un sistema de vigilancia epidemiológica técnicamente idóneo) en una situación en la que esta información de base poblacional se encuentra disponible en un número limitado de Comunidades Autónomas. Esta información se complementa a su vez con la obtenida de otras fuentes mediante metodologías variadas. Las encuestas de seroprevalencia por el procedimiento anónimo no relacionado o la seroprevalencia en personas que acuden a realizarse la prueba diagnóstica a determinados centros, como los centros de enfermedades de transmisión sexual (ETS) o similares, son dos ejemplos de estas otras fuentes complementarias.

Los Centros de ETS han tenido, y previsiblemente tendrán todavía más en el futuro, un papel privilegiado en la obtención de esta información. Un buen ejemplo de ello es el Grupo EPI-VIH. Con la participación de un amplio número de profesionales y financiado por la Fundación para la Prevención y la Investigación del SIDA en España, FIPSE, el Grupo EPI-VIH ha contribuido de manera importante a conocer el estado y la evolución de la epidemia de VIH/SIDA en nuestro país, y muestra de ello son las más de 40 publicaciones y comunicaciones nacionales e internacionales y las varias tesis doctorales fruto de esta labor. Las poblaciones que acuden a realizarse la prueba son seleccionadas (la prevalencia del VIH de adultos jóvenes en nuestro país se sitúa alrededor del $0,3 \%{ }^{10}$ 
en población general y del $1 \%$ en la población que acude a hacerse la prueba a estos centros), y dependen además de las características, localización y funcionamiento de cada uno de los centros. Considerando adecuadamente estos factores en el momento de la interpretación de los datos, la información obtenida de esta forma y complementada con la vigilancia epidemiológica de otras ETS resulta de inestimable valor y debe ser mantenida y potenciada en el futuro. La incidencia de ETS tiene un especial interés desde la perspectiva del VIH/sida. Esta incidencia informa de forma indirecta sobre el nivel de riesgo para la transmisión sexual del VIH en la población y, debido a que las ETS potencian el riesgo para la transmisión de VIH en las exposiciones de riesgo, informa además de este riesgo añadido.

Por último, un tercer nivel de vigilancia epidemiológica de la epidemia lo constituye la información relativa a las conductas de riesgo. En España, en relación a los hábitos sexuales de la población general adulta, disponemos de la valiosa información obtenida este año de la Encuesta de Salud y Hábitos Sexuales gracias a una fructífera colaboración entre el Instituto Nacional de Estadística y el Misterio de Sanidad y Consumo/Plan Nacional sobre el Sida ${ }^{11}$. Existen además, de forma específica, numerosos estudios de calidad e información relativa a otras conductas de riesgo o centrados en poblaciones especialmente vulnerables.

De esta forma y tras una labor de cuidadosa agregación e interpretación de los datos es como conocemos la realidad del VIH/sida en nuestro país. Una realidad que resulta cambiante, especialmente en lo que se refiere a la principal vía de transmisión del VIH.

La principal vía de transmisión del VIH durante las dos primeras décadas de la epidemia en España fue compartir material de inyección entre usuarios de drogas inyectadas (UDIs) ${ }^{2}$. Sin embargo esta situación ha cambiado recientemente y estamos asistien- do a una «sexualización» de la epidemia. La vía de transmisión más frecuente es hoy la vía sexual, y sobre todo la heterosexual. La proporción de personas recientemente diagnosticadas de infección por VIH cuya vía de transmisión fue la heterosexual es creciente en nuestro país, de forma que el VIH/SIDA se asimila hoy en día más que nunca a una enfermedad de transmisión sexual ${ }^{2,12,13}$.

Los UDIs en nuestro país han sido fundamentalmente hombres, por lo que la epidemia ha tenido y sigue teniendo todavía hoy predominio entre los hombres. Únicamente el incremento en la proporción de casos de transmisión heterosexual y la vulnerabilidad de la mujer al VIH hacen prever una proporción creciente de diagnósticos en mujeres. Todo ello quiere decir que la epidemia cambia su forma, su composición, pero no significa que estemos asistiendo a un incremento en el número de casos o a un repunte de los mismos en población general. Con los datos disponibles en España los casos de nuevas infecciones por VIH en población general parecen mantener una tendencia descendente.

A pesar de ello son diversos los signos que deben hacernos estar alerta. Son varios los países de Europa Occidental que están detectando incrementos en los nuevos diagnósticos de VIH y no únicamente atribuibles a la realización de un mayor número de pruebas diagnósticas, si no a incrementos reales de nuevos $\operatorname{casos}^{14,15}$. Además, en nuestro país se han comenzado a detectar aumentos en la incidencia de otras ETS ${ }^{16}$ y la información sobre el nivel de utilización del preservativo, aunque se ha incrementado de forma muy sensible a lo largo de los años, está lejos de los niveles óptimos ${ }^{11}$. Se pone de manifiesto la persistencia de prácticas sexuales de riesgo en la población genera ${ }^{1}$.

Para concluir, resaltar que nos encontramos ante una epidemia de una enfermedad transmisible, prevenible, no curable, cambiante en sus vías más frecuentes de transmi- 
sión, que se transmite por prácticas de riesgo que persisten en la población, que está experimentando incrementos en países de nuestro entorno y que continua, en definitiva constituyendo un importante problema de salud pública. Y es en este contexto donde la necesidad de disponer de un sistema de información de base poblacional de calidad resulta claramente indiscutible. Administraciones, organizaciones no gubernamentales y profesionales socio-sanitarios, debemos asumir y ejercer nuestras respectivas responsabilidades para dar la respuesta óptima necesaria para el control de la epidemia de VIH/SIDA en España.

\section{BIBLIOGRAFÍA}

1. Cascade. Time from HIV-1 seroconversion to AIDS and death before the widespread use of highly -active antirretroviral therapy: a collaborative re-analysis. Collaborative Group on AIDS Incubation and HIV survival including CASCADE EU Concerted Action. Concerted Action on SeroConversion to AIDS and Death in Europe. Lancet 2000, 355:1131-7.

2. Secretaría del Plan Nacional sobre el sida. VIH y Sida en España. Situación epidemiológica 2001. Madrid: Ministerio de Sanidad y Consumo; 2002.

3. Registro Nacional de Casos de Sida y registros Autonómicos. Vigilancia epidemiológica del SIDA en España. Actualización a 30 de junio de 2004. Disponible en: http://cne.isciii.es/htdocs/sida/sidavih.htm.

4. CDC. 1993 Revised classification system for HIV infection and expanded surveillance case definition for AIDS among adolescents and adults. MMWR 1992;41(no. RR-17).

5. Egger M, May M, Chene G, Phillips AN, Ledergerber B, Dabis F, et al. Prognosis of HIV-1 infected patients starting highly active antiretroviral therapy: a collaborative analysis of prospective studies. Lancet 2002, 360:119-29.
6. Eurosurveillance. European Communicable Disease Bulletin. 1998;3(5):51.

7. JAIDS. HIV/AIDS Surveillance in a New Era. 2003; 32 (Suppl 1)

8. González R, Sacristán A, Valero LF, Sáenz MC, Epidemiología de la infección por virus de inmunodeficiencia humana (VIH) en la provincia de Salamanca (1985-2002). Enferm Infecc Microbiol Clin $2004 ; 22(5) 272-8$

9. Centres for Disease Control and Prevention. Guidelines for national human immunodeficiency virus case surveillance, including monitoring for human immunodeficiency virus infection and acquired immunodeficiency syndrome. MMWR 1999;48(RR13):1-28.

10. Castilla J, Pachón I, González MP, Amela C, Muñoz L, Tello O et al. Seroprevalence of HIV and HTLV in a representative sample of Spanish population. Epidemiol Infect 2000; 125:159-62.

11. Instituto Nacional de Estadística y Ministerio de Sanidad y Consumo. Encuesta de Salud y Hábitos sexuales. Madrid: Instituto Nacional de Estadística; 2004. Disponible en: www.ine.es.

12. Centre d'estudis Epidemiològics sobre l'HIV/SIDA de Catalunya (CEESCAT). Sistema Integrat de Vigilància Epidemiològica de l'HIV/SIDA (SIVES) 2003.

13. Zulaika D, Aguirrebengoa K, Andía A, Arrizabalaga J, Bustillo JM, Cámara MM et al. Características epidemiológicas de las nuevas infecciones causadas por el VIH comparadas con los casos de sida. La epidemia de VIH/sida en el País Vasco. Gac Sanit 2004; 18:145-9.

15. European Centre for the Epidemiological Monitoring of AIDS. WHO and UNAIDS Collaborating Centre on AIDS. (Euro HIV). HIV/AIDS Surveillance in Europe. End Year report 2003. 2004; 70.

16. ONUSIDA/OMS. Situación de la epidemia de SIDA. Diciembre de 2004. Disponible en: http://www.unaids.org.

17. Vall Mayans M, Sanz Colomo B, Loureiro Varela E, Armengol Egea P. Infecciones de transmisión sexual en Barcelona más allá del 2000. Med Clin (Barc) 2004; 122(1): 18-20. 